\title{
OPTIMIZING THE ROBOT ARM MOVEMENT TIME USING VIRTUAL REALITY ROBOTIC TEACHING SYSTEM
}

\author{
Tahriri, F. ; Mousavi, M. ; Yap, H. J. ; Siti Zawiah, M. D. ${ }^{*} \&$ Taha, Z. .* \\ * Department of Mechanical Engineering, Faculty of Engineering, University of Malaya, \\ 50603 Kuala Lumpur, Malaysia \\ ** Faculty of Mechanical Engineering, Universiti Malaysia Pahang, 26600 Pekan, \\ Pahang Darul Makmur, Malaysia \\ E-Mail: Farzad_Tahriri@hotmail.com
}

\begin{abstract}
Robots play an important role in performing operations such as welding, drilling and screwing parts in manufacturing. Optimizing the robot arm movement time between different points is an important task which will minimize the make-span and maximize the production rate. But robot programming is a complex task whereby the user needs to teach and control the robot in order to perform a desired action. In order to address the above problem, an integrated 3-dimensional (3D) simulation software and virtual reality (VR) system is developed to simplify and speed up tasks and therefore enhance the quality of manufacturing processes. This system has the capability to communicate, transfer, optimize and test the data obtained from the VR and 3D environment to the real robot in a fast and efficient manner. In addition, this system eliminates the need for robot programming, and thus it is easily implemented by users with limited engineering knowledge. The optimization model is tested on a test case, in which the data are extracted from the VR system. The results show an increase in production rate and a decrease in cycle time when the make-span is minimized. The virtual reality robotic teaching system (VRRTS) offers several benefits to users, and will therefore surpass complex and time-intensive conventional robot programming methods.

(Received in November 2013, accepted in June 2014. This paper was with the authors 1 month for 1 revision.)
\end{abstract}

Key Words: Robot Traveling Time, Virtual Reality, Robotics, Teaching System, Optimization, Flexible Manufacturing System

\section{INTRODUCTION}

Nowadays, with the upsurge in market competition, automated or robotic form of operations such as welding, suction, drilling and screwing parts are increasingly required [1]. However, the programming of the robots is an intricate and time consuming task. VR is one of the promising technologies which can significantly simplify tasks and even eliminate robot programming.

\subsection{Robots in flexible manufacturing systems}

Industrial robots are widely used in numerous flexible manufacturing systems in order to improve efficiency and quality [2]. Robots with vastly different capabilities and specifications are available for a wide range of applications [3]. The most typical anthropomorphic or human like characteristic of a robot is its arm. The arm, together with the robot's capacity to be programmed, makes it ideally suited for a variety of production tasks, including machine loading, spot welding, spray painting, as well as assembly of parts such as screwing and drilling [4-6]. Flexibility and automation in assembly lines can be achieved by the use of robots [7]. The robot can be programmed to perform a sequence of mechanical motions, and it can perform the motion sequence repeatedly until it is reprogrammed to perform other sequences $[8,9]$. The robotic assembly line problem arises when there are different assembly tasks to be assigned [10]. This problem involves assigning tasks based on the assembly 
sequence, operation time and robot arm movement time. Robot arm movement time refers to the total elapsed time to move a unit of work from the beginning to the end of a physical process. Optimizing the robot arm movement time can positively minimize the make-span and maximize the production rate of the line [11].

\subsection{Virtual reality}

Virtual reality (VR) is a human-computer interface which responds in an interactive way to the behavior of the user. VR technology can be very helpful in visualizing complicated 3D models of parts and assemblies. Additionally, VR can be used to visualize how parts fit together and understand their spatial interrelationships. Another application of VR involves simulating situations where companies need to test new products, or where there are hazardous environments which require preventing employee exposure to unnecessary risks such as painting, screwing and drilling using the robot arm [12]. Using VR in manufacturing applications such as layout planning, assembly line scheduling and sequencing prevents costly mistakes in planning and building processes. The production assembly line design is an important part of the manufacturing system design, which is closely related to the production line equipment utilization rate, the production cycle time and the efficiency of the production line [13].

New technologies have emerged in recent years, which enable flexible designs to be incorporated into production assembly lines involving complicated tasks, and the system can be simulated prior to execution of the real system. In this regard, VR is one of the main technologies implemented in manufacturing systems. Table I shows the VR benefits in a number of areas in the manufacturing process.

Table I: VR benefits in the manufacturing process [14].

\begin{tabular}{|c|c|}
\hline Area & Benefits \\
\hline Design & $\begin{array}{l}\text { Enables the whole design team to work together in a Virtual Environment (VE). } \\
\text { Improves visualization of the product by allowing the user to coexist in the same environment as the } \\
\text { product model. } \\
\text { Improves interaction with the design in terms of a more intuitive model manipulation and functional } \\
\text { experimentation. }\end{array}$ \\
\hline Prototyping & $\begin{array}{l}\text { Significantly reduces the amount of hardware prototypes during conception, design and evaluation of new } \\
\text { products. } \\
\text { Provides a VE for innovating, testing and evaluating specific characteristics of a candidate design. }\end{array}$ \\
\hline Planning & $\begin{array}{l}\text { Improves the understanding of the plans and supports interdisciplinary discussions. } \\
\text { Allows users to interact and change the model during runtime. } \\
\text { Enables unskilled users to understand and participate in the planning process. } \\
\text { Supports technological as well as the economic modelling of diverse production planning scenarios. }\end{array}$ \\
\hline Simulation & $\begin{array}{l}\text { Convinces the use of simulation tools. } \\
\text { Verifies and validates the simulation model. } \\
\text { Enables the user to understand the results. } \\
\text { Provides a VE for communicating the results. } \\
\text { Achieves the credibility for the simulation [15]. }\end{array}$ \\
\hline Training & $\begin{array}{l}\text { Duplicates an entire manufacturing process to a VE to give trainers their own factory to learn in. } \\
\text { Provides users with an environment to explore the outcomes of their decision without risking themselves } \\
\text { or their equipment. } \\
\text { Allows employees to practice existing and new tasks safely. }\end{array}$ \\
\hline Machining & $\begin{array}{l}\text { Evaluates the feasibility of a part design and selection of processing equipment. } \\
\text { Allows users to study the factors affecting the quality, machining time and cost based on modelling and } \\
\text { simulation. }\end{array}$ \\
\hline Assemble & $\begin{array}{l}\text { Reduces design cycle time, redesign efforts and design prototypes [16]. } \\
\text { Predicts the quality of an assembly, product cycle and costs. } \\
\text { Addresses assembly and disassembly verification. }\end{array}$ \\
\hline Inspection & $\begin{array}{l}\text { Models and simulates the inspection process, and the physical and mechanical properties of the inspection } \\
\text { equipment. } \\
\text { Provides an environment for studying inspection methodologies, collision detection, inspection plan, } \\
\text { factors affecting the accuracy of the inspection process, etc. [17]. }\end{array}$ \\
\hline
\end{tabular}


This paper presents a heuristic mathematical model for determining the optimal sequence of robot movement in order to minimize the make-span and maximize the number of production units per day in the case of robot cells. Virtual reality technology is used to allow the user to teach the robot in a virtual environment and make it easier and less complicated for users.

\section{METHODOLOGY}

The first step of the methodology involves creating the 2D drawing using AutoCAD software. The $2 \mathrm{D}$ drawing is the output of the AutoCAD software and is considered as a starting point for the entire process [18]. The second step involves creating the 3D models based on the above output. The models are developed using solid modelling software, which mimic the actual set-up in the laboratory. These samples should be exported in stereolithography (ASCII) format before loading into the 3D CAD model generator and visualization software (ModGenSTL). The output of ModGenSTL is a file format having the extension ' $D M G$ ' and Models are re-rendered using OpenGL-API. The computer graphics are not only used to define the shape and geometry of the objects, but also to describe the spatial behavior of the virtual objects. A database is created to store all information regarding the $3 \mathrm{D}$ models and the virtual environment. This information includes the physical properties and dynamic behavior of the models. The data from the input devices are also stored in the database $[19,20]$. The whole process is summarized in Fig. 1. Following this, the 3D models are exported into the virtual reality system. The user may import, move and rotate the parts in the virtual environment in order to identify the points which the robots will consider as the basic points in real environment. The virtual software assumes that 'parts' are objects that are free to move or can be gripped by the robot, whereas 'stations' are objects that are usually static or cannot be gripped by the robot. The user keys in the station, unit parts and robot in the simulation software. Fig. 2 shows the robot, part and station imported into the software.

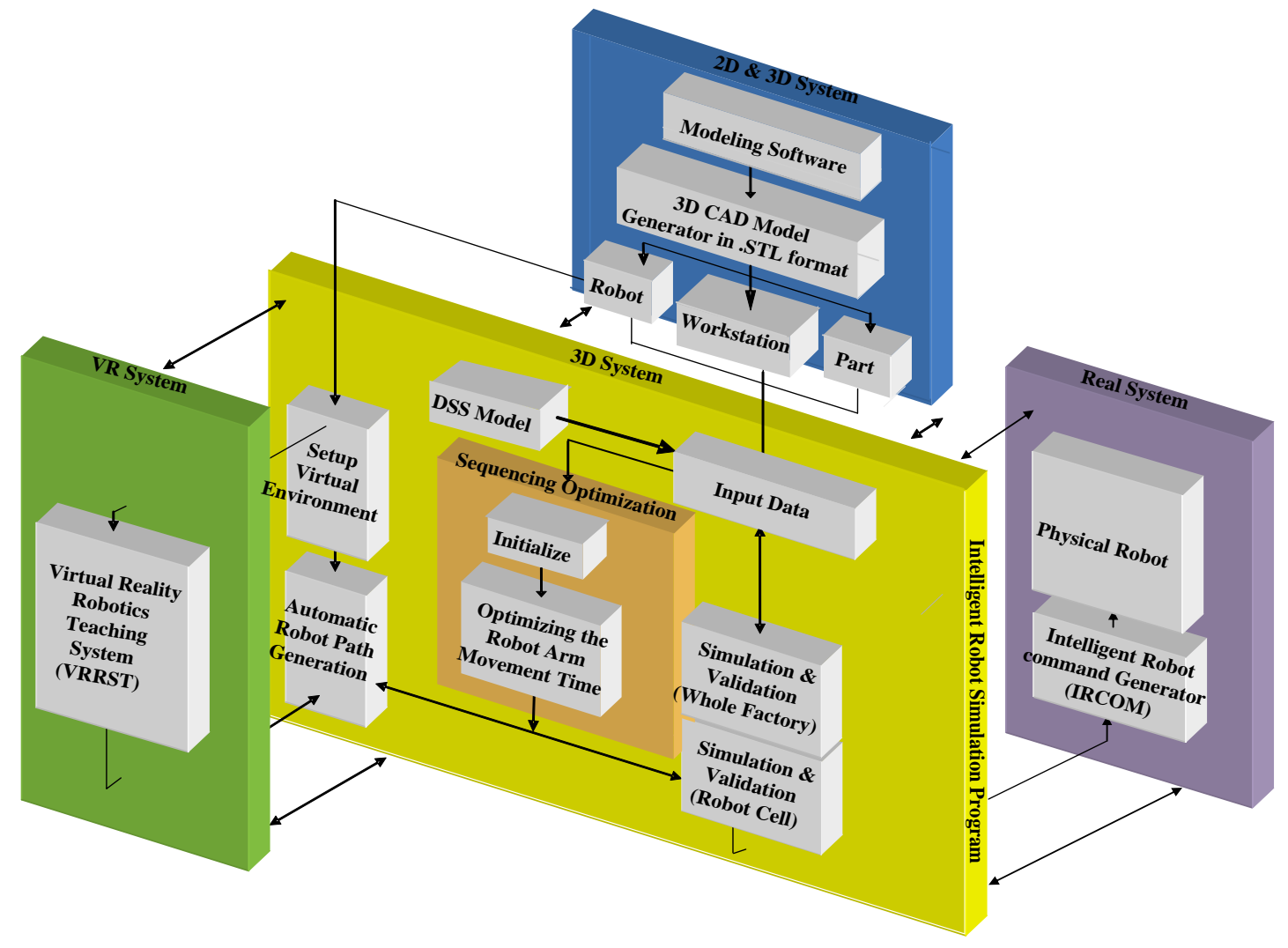

Figure 1: Summary of research process. 


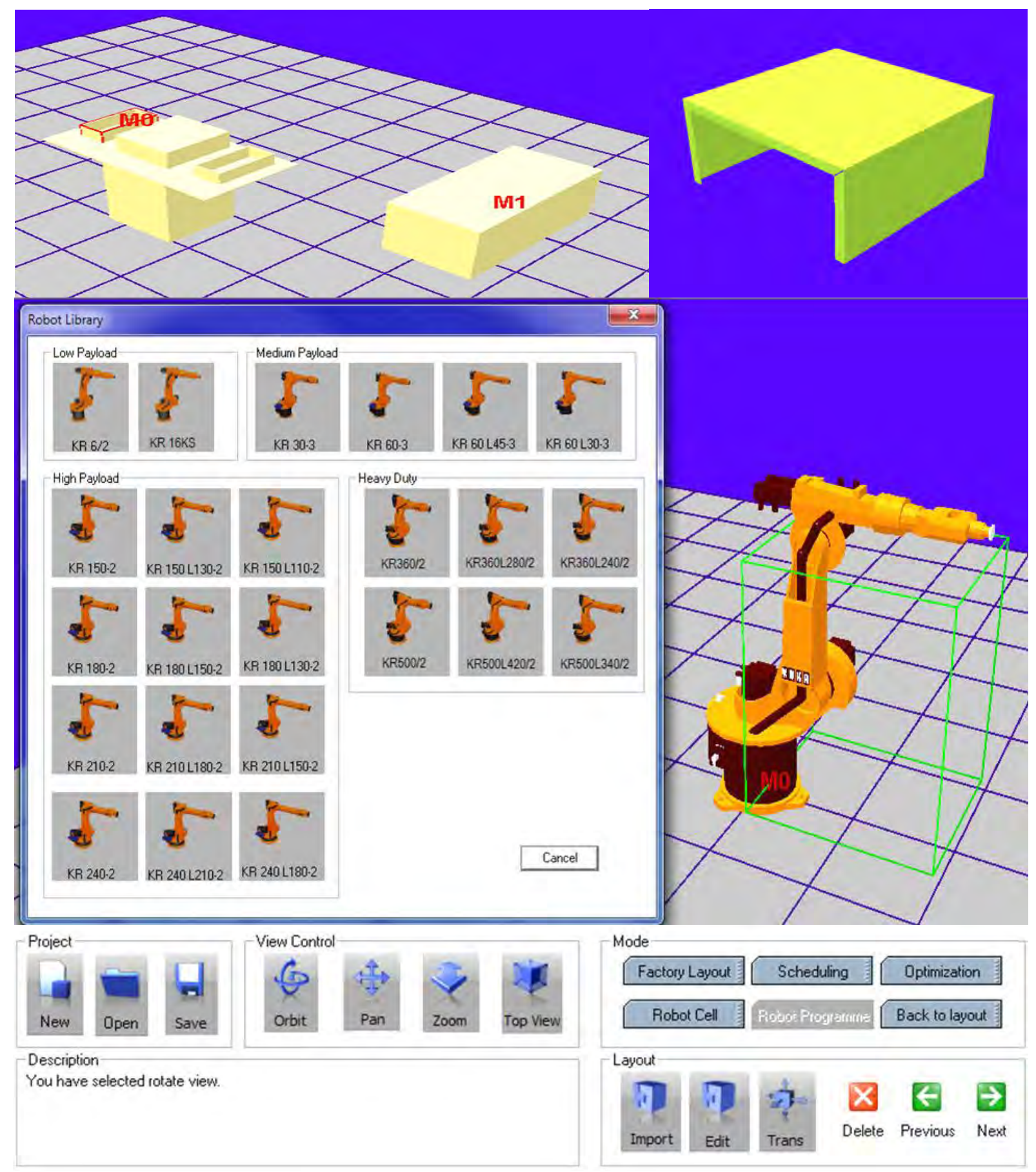

Figure 2: Robot, part and station imported into the software.

The virtual teaching system consists of a series of objects, which can be viewed from various positions and angles. The programmer will feel himself/ herself as part of the virtual environment via real-time updating of stereoscopic images. The programmer works with the virtual objects in order to complete the desired task. Therefore a physical environment for simulation workstation is required to make the users feel, see and interact with objects in the most natural and ergonomic position. The simulation workstation should be collocated between the 3D view, virtual objects and the user's hand. The user can see and interact with the virtual objects at the same place, as shown in Fig. 3. The structure of the platform is tested during the design stage in order to ensure that the platform is capable of supporting the weight of the equipment such as monitor. An adjustable platform is designed to fulfill the variations in human anatomy. The user may feel as though he or she is in a work cell with the aid of $3 \mathrm{D}$ 
glasses, data gloves and sensor tracker [19]. The user can show the points onto which the robots should screw. The successful environment will be saved and loaded into the VRRTS for robot teaching. The robot simulation system is developed based on $\mathrm{C} / \mathrm{C}++$ programming language with OpenGL. After filtering, the new set of data is sent to the simulator. The simulator has the capacity of real-time simulation of a virtual KUKA robot through 3D animation of a personal computer. The user is able to control and visualize the virtual robot through a user-friendly interface by using the mouse or keyboard. The movement of the virtual robot can be simulated numerous times, once the filtered data has been loaded. The user may change the viewing angle or zoom from any position according to his or her preference.

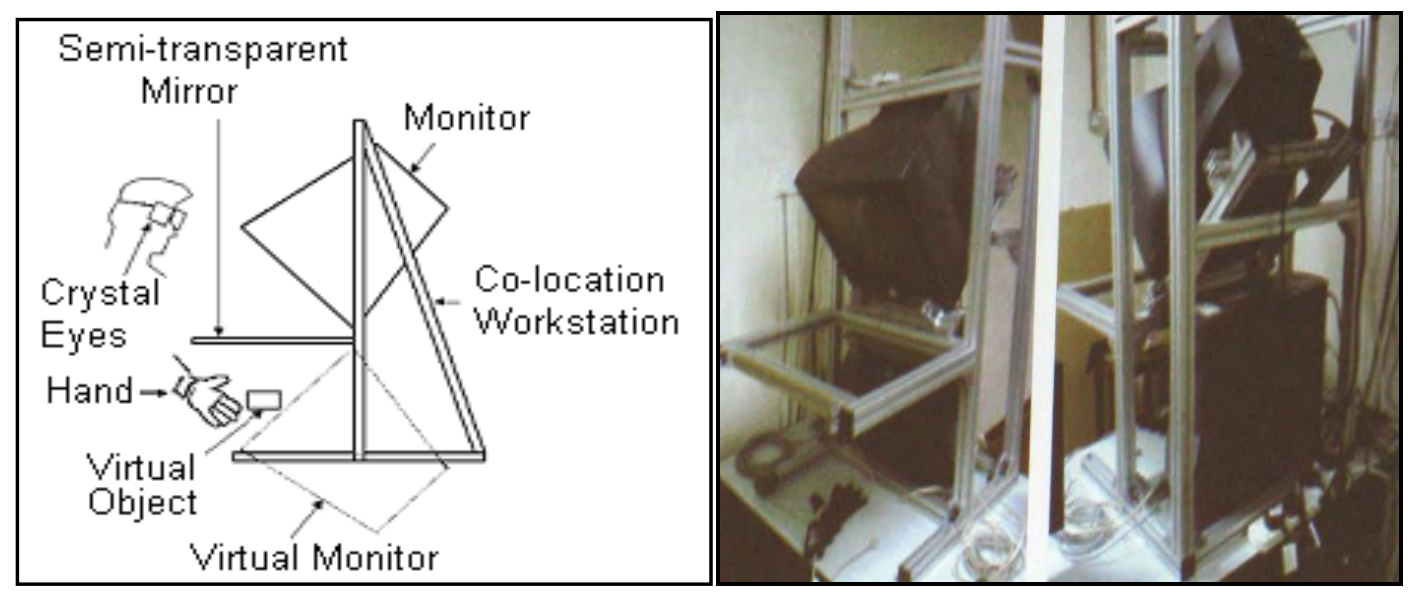

Figure 3: Co-location workstation [19].

The processed data obtained from the VRRST is a series of arrays. An automatic robot path generation algorithm is developed in order to generate a complete robot path based on the processed data. The algorithm generates the intermediate teaching points within the processed data which are required by the robot. Fig. 4 shows the virtual objects and simulated robot workstation based on the actual laboratory set-up.

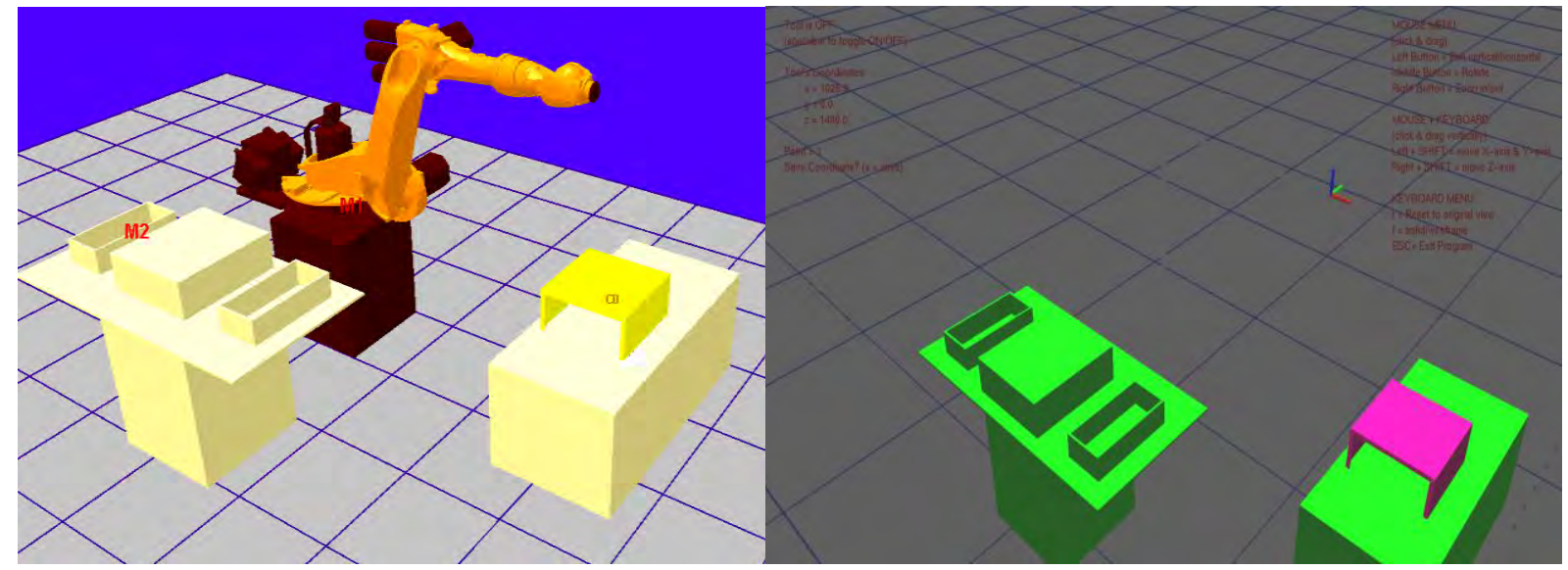

Figure 4: Virtual objects and actual laboratory set-up.

After reading each line of the processed data generated from the VR and simulation system, the data will be converted into a text file and will be transferred to the robot optimization travelling time algorithm in order to determine the optimum task sequence based on the points that the robot was taught, as shown in Fig. 5. Fig. 6 shows the sequence of the robot arm movement timein a robot cell. The dependent variables are shown in Table II. 


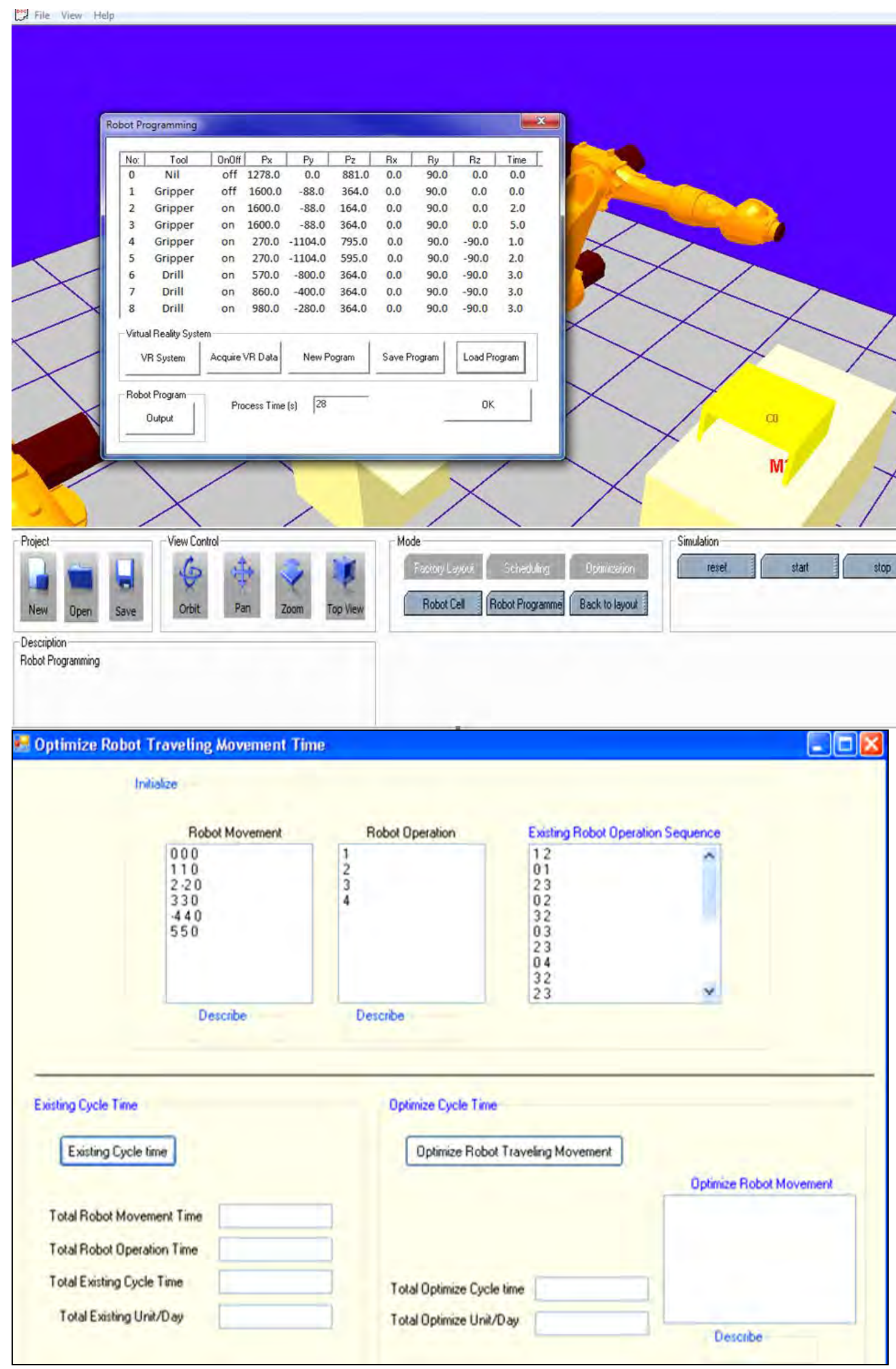

Figure 5: Robot travelling optimization dialog box.

The travelling salesman problem is a combinatorial problem with numerous solutions and therefore it is deemed impossible to probe the problem by using analytical methods. The 
algorithm presents the number of target locations ( $N$ points) that can be considered for optimization. The objective here is to perform drilling and screwing, neglecting the sequence using the mathematical formula. Planning the robot paths is more complex than the typical travelling salesman problem due to the fact that the problem does not merely involve the minimization of the distance travelled. The robot arm does not have a single velocity. Velocity is highly dependent on the type and direction of the motion, and therefore different degrees of freedom have different acceleration, deceleration and velocity characteristics. The velocity of the robot arm is set constant in this algorithm.

Table II: Dependent variables.

\begin{tabular}{|l|l|}
\hline Variables & Description of variables \\
\hline$R 1$ & Minimum Reach of Robot Arm \\
\hline$R 2$ & Maximum Reach of Robot Arm \\
\hline$V_{r}$ & Velocity of Robot Arm \\
\hline$I$ & Start Position \\
\hline$F$ & Finish Position \\
\hline$O P_{i}$ & Operation Time \\
\hline$\delta_{i}^{j}(x, y, z)$ & Robot Movement Distance \\
\hline$E R_{T}$ & Existing Robot Arm Movement Time \\
\hline$O R_{T}$ & Optimum Robot Arm Movement Time \\
\hline$T E_{U}$ & Existing Total Number of Units Produced per Day \\
\hline$T O_{U}$ & Optimum Total Number of Units Produced per Day \\
\hline$M i n \delta_{i j}$ & Minimum Robot Travelling Distance \\
\hline$H$ & Working Hour per Day \\
\hline$P i_{(x, y, z)}$ & Part Position \\
\hline$S_{k}(k=0,1, \ldots)$ & Sequence \\
\hline
\end{tabular}

The existing robot arm movement time is determined using Eq. (1),

$$
\begin{aligned}
& E R_{T}=\left(\frac{V_{r}}{\sum_{i=n}^{j=m}\left(\int \delta_{i}^{j}=\sqrt{\left(x_{j}+x_{i}\right)^{2}+\left(y_{j}+y_{i}\right)^{2}+\left(z_{j}+z_{i}\right)^{2}}\right)}+\sum_{i=0}^{n} O P i\right) \\
& T E_{U}=\frac{E R_{T}}{H}
\end{aligned}
$$

where $E R_{T}$ represents the existing robot arm movement time and $T E_{U}$ represents the total existing units produced per day.

The optimum robot arm movement time is determined using Eq. (2),

$$
\begin{aligned}
& O R T=\left(\frac{V_{r}}{\operatorname{Min} \sum_{i=n}^{j=m}\left(\int \delta_{i}^{j}=\sqrt{(x j-x i)^{2}+(y j-y i)^{2}+(z j-z i)^{2}}\right)}+\sum_{i=0}^{n} O P i\right) \\
& T O_{U}=\frac{O R_{T}}{H}
\end{aligned}
$$

where $O R_{T}$ represents the optimum robot arm movement time and $T O_{U}$ represents the total optimum units produced per day.

It shall be highlighted that the robot arm movement time and total number of units produced per day are optimized based on the following criteria:

$$
\begin{aligned}
& E R_{T}<O R_{T} \\
& T E_{U}<T O_{U}
\end{aligned}
$$




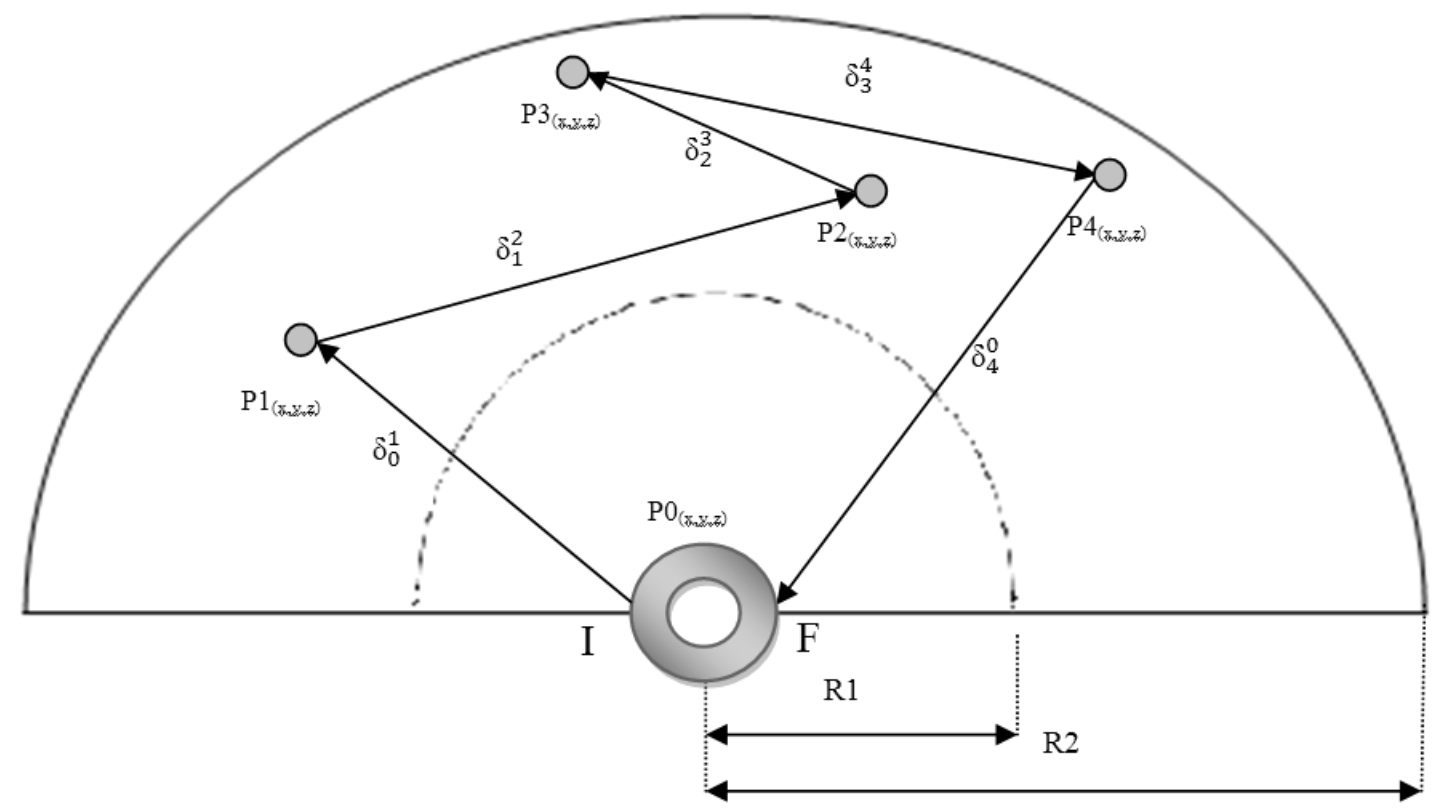

Figure 6: Alternative sequences of robot arm movement time in a robot cell.

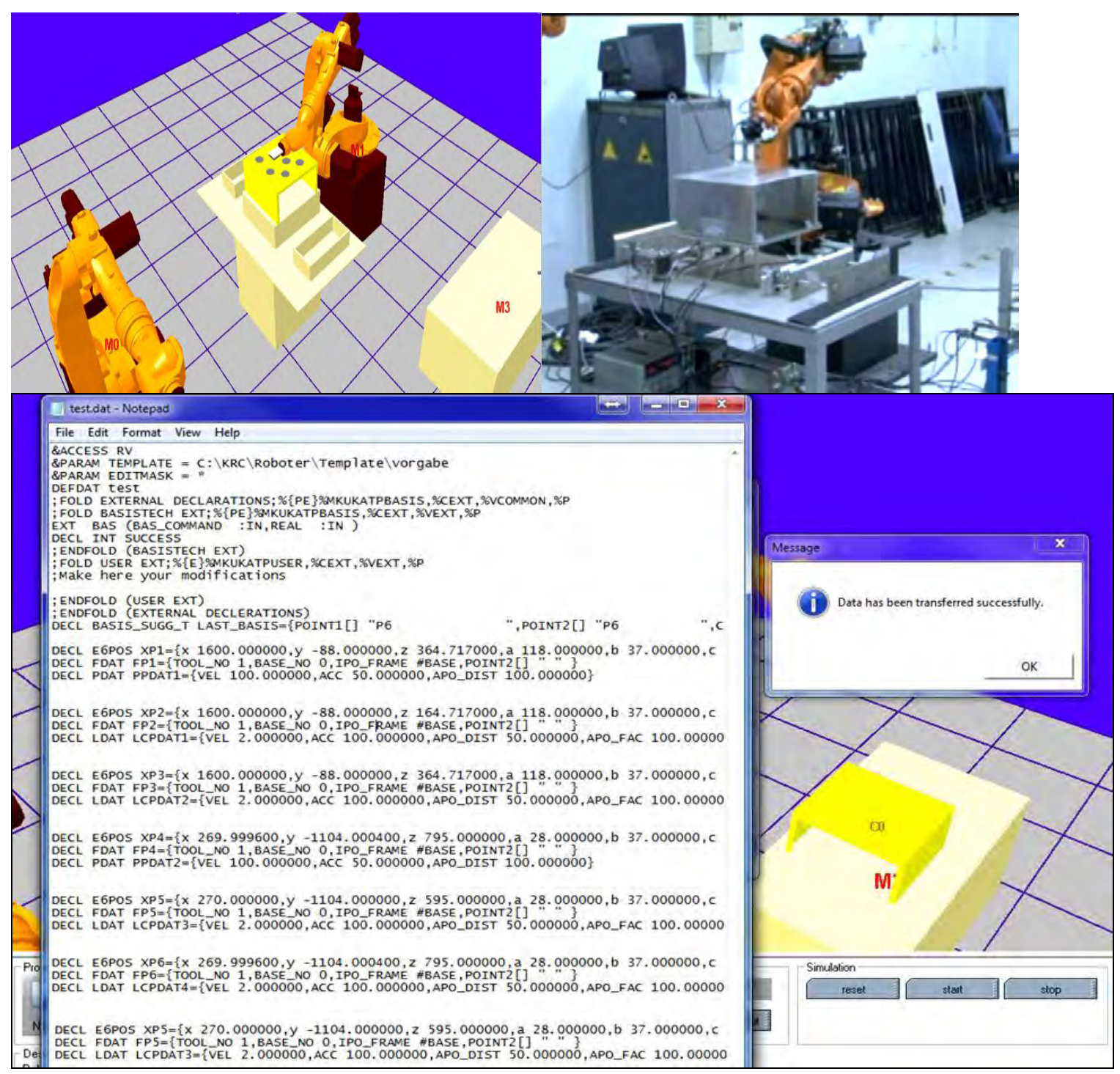

Figure 7: Data encoding from the 3D simulation software and transferring the data to the actual robot. 
After optimizing the task sequence of the robot traveling time, the data generated from the VR system and optimization algorithm are transferred into the simulation software for validation, testing and simulation. Once the user is satisfied with the optimization process in the simulation software, the database can be translated into KUKA robot language using a command generator or postprocessor. The commands are then sent to the actual robot for task execution. The output commands generated by the post-processor is tested by the controller of the KUKA robot (Model: KRC6), as shown in Fig. 7.

\section{RESULTS AND DISCUSSION}

The robot arm movement time optimization model is tested using a real test case which involves a screwing process. The test is carried out using the KUKA robot (Model: KRC6) located at the Robotics Laboratory, Faculty of Engineering, University of Malaya. The VR system retrieves the screwing task data from the user and the data is transferred into the $3 \mathrm{D}$ simulation software. The heuristic optimization tool is designed into a single package which integrates discrete-event, geometric simulation and virtual reality environment. The software optimizes the task sequence of the screwing points to alleviate the time of the robot's movement. The results show that the screwing task of the existing robot produces a total number of 38 units per day with a total cycle time of 12.4 minutes. However, it is found that the total number of units produced per day has increased to 43 units and the total cycle time is reduced to 11.13 minutes upon optimization. The test case reveals an increase in production rate and a decrease in total cycle time when the robot arm movement time optimization model is implemented, as shown in Fig. 8.

The above test demonstrates that the RTT heuristic algorithm offers several advantages for users as follows:

- The existing cycle time for each complete process cycle can be identified;

- The existing total number of units produced per day can be determined;

- The optimal sequence of the screwing task can be determined; and

- The robot arm movement time can be optimized, which in turn increases he total number of units produced per day, reduces the overall cycle time and reduces robot idle time.

Furthermore, the VR system offers other benefits such as ease of supplying input data from the VR system to the RTT model, making robot programming simpler, faster and efficient. This eliminates the need for robot programming, which will be beneficial for users with limited engineering knowledge. These benefits will greatly facilitate manufacturing enterprises to meet deadlines, decrease inventories and improve efficiency of assembly systems by optimizing the robot arm movement time.

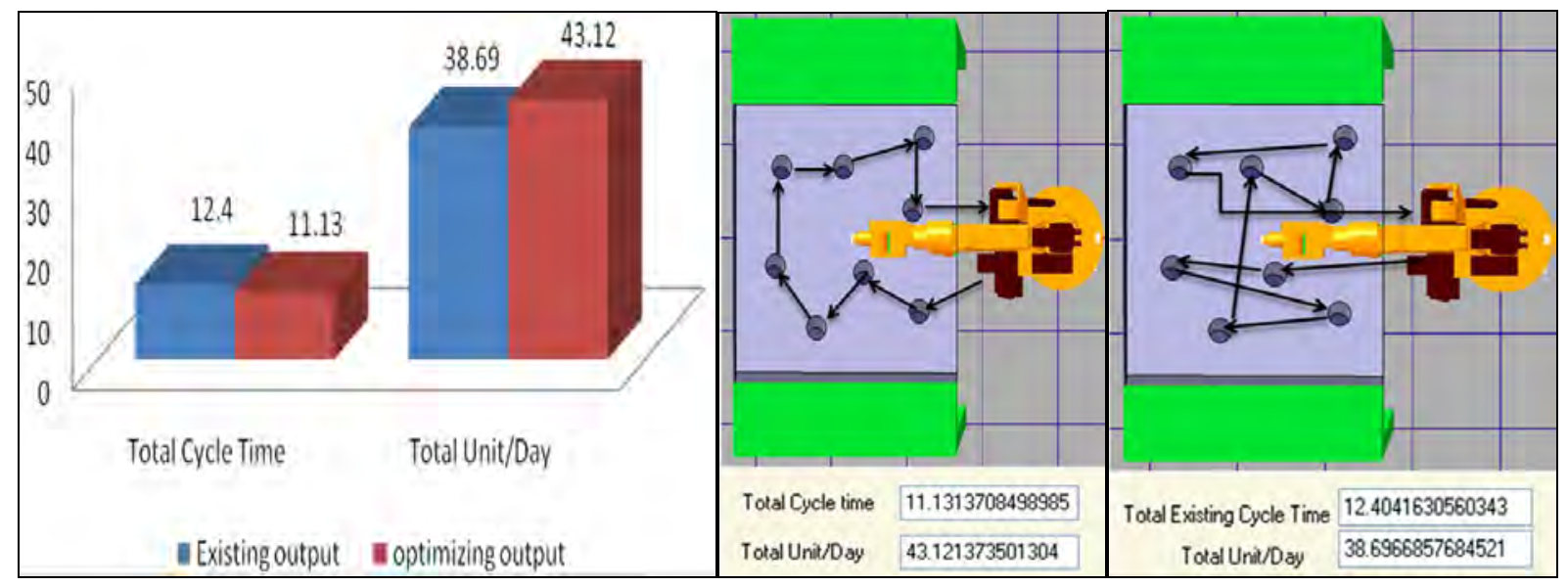

Figure 8: Existing and optimum robot arm movement time and total number of units produced per day. 


\section{CONCLUSION}

In this paper, a heuristic mathematical model has been developed using VRRTS to optimize the robot arm movement time, which minimizes make-span and maximizes the total number of units produced per day in robot cells. In this model, the user keys in the station, unit parts and robot into the simulation software after creating 3D files and sending them to the VR system. The processed data generated from the VRRST creates the intermediate teaching points within the processed data which are required by the robot. The data is converted into a text file and transferred to the robot arm movement time optimization algorithm in order to determine the optimum task sequence. The results produced by the VR system and the optimization algorithm are then transferred to the simulation software for validation, testing and simulation. The simulation data are run directly on a real KUKA robot based on a real test case. The results show a $10.24 \%$ decrease in cycle time and $10.27 \%$ increase in the total number of units produced per day. The system is presently under development in order to improve the performance and robustness of the VR simulation system. This system will be modified in the near future, in which scheduling and layout for robot cell optimization will be incorporated into the system.

\section{ACKNOWLEDGEMENT}

The authors would like to acknowledge the financial support provided by the Malaysian Ministry of Higher Education (MOHE) under the High Impact Research Grant (Grant No. UM.C/HIR/MOHE/ENG/35 (D000035-16001)).

\section{REFERENCES}

[1] Bozek, P. (2013). Robot path optimization for spot welding applications in automotive industry, Technical Gazette, Vol. 20, No. 5, 913-917

[2] Parkan, C.; Wu, M.-L. (1999). Decision-making and performance measurement models with applications to robot selection, Computers \& Industrial Engineering, Vol. 36, No. 3, 503-523, doi:10.1016/S0360-8352(99)00146-1

[3] Rao, R. V.; Padmanabhan, K. K. (2006). Selection, identification and comparison of industrial robots using digraph and matrix methods, Robotics and Computer-Integrated Manufacturing, Vol. 22. No. 4, 373-383, doi:10.1016/j.rcim.2005.08.003

[4] Levitin, G.; Rubinovitz, J.; Shnits, B. (2006). A genetic algorithm for robotic assembly line balancing, European Journal of Operational Research, Vol. 168, No. 3, 811-825, doi:10.1016/j.ejor.2004.07.030

[5] Zhang, Q.; Li, M.; Wang, X.; Zhang, Y. (2012). Reinforcement Learning in Robot Path Optimization, Journal of Software, Vol. 7, No. 3, 657-662, doi:10.4304/jsw.7.3.657-662

[6] Zhang, Y.; Gong, D.-W.; Zhang, J.-H. (2013). Robot path planning in uncertain environment using multi-objective particle swarm optimization, Neurocomputing, Vol. 103, 172-185, doi:10.1016/j.neucom.2012.09.019

[7] Asfahl, C. R. (1992). Robots and manufacturing automation, John Wiley \& Sons, New York

[8] Viswanadham, N.; Narahari, Y. (1992). Performance modeling of automated manufacturing systems, Prentice-Hall, Englewood Cliffs

[9] Sethi, S. P.; Sriskandarajah, C.; Sorger, G.; Blazewicz, J.; Kubiak, W. (1992). Sequencing of parts and robot moves in a robotic cell, International Journal of Flexible Manufacturing Systems, Vol. 4, No. 3-4, 331-358, doi:10.1007/BF01324886

[10] Gao, J.; Sun, L.; Wang, L.; Gen, M. (2009). An efficient approach for type II robotic assembly line balancing problems, Computers \& Industrial Engineering, Vol. 56, No. 3, 1065-1080, doi:10.1016/j.cie.2008.09.027

[11] Taha, Z.; Tahriri, F.; Zuhdi, A. (2011). Job sequencing and layout optimization in virtual production line, Journal of Quality, Vol. 18, No. 4, 351-374 
[12] Faieza Aziz, A.; Mousavi, M. (2009). A review of haptic feedback in virtual reality for manufacturing industry, Journal of Mechanical Engineering, Vol. 40, No. 1, 68-71

[13] Novak-Marcincin, J.; Brazda, P.; Janak, M.; Kocisko, M. (2011). Application of virtual reality technology in simulation of automated workplaces, Technical Gazette, Vol. 18. No. 4, 577-580

[14] Mujber, T. S.; Szecsi, T.; Hashmi, M. S. J. (2004). Virtual reality applications in manufacturing process simulation, Journal of Materials Processing Technology, Vol. 155-156, 1834-1838, doi:10.1016/j.jmatprotec.2004.04.401

[15] Rohrer, M. W. (2000). Seeing is believing: the importance of visualization in manufacturing simulation, Proceedings of the Winter Simulation Conference 2000, Vol. 2, 1211-1216

[16] Jayaram, S.; Connacher, H. I.; Lyons, K. W. (1997). Virtual assembly using virtual reality techniques, Computer-Aided Design, Vol. 29, No. 8, 575-584, doi:10.1016/S00104485(96)00094-2

[17] Lee, W. B.; Cheung, C. F.; Li, J. G. (2001). Applications of virtual manufacturing in materials processing, Journal of Materials Processing Technology, Vol. 113, No. 1-3, 416-423, doi:10.1016/S0924-0136(01)00668-9

[18] Antic, A.; Hodolic, J.; Sokovic, M. (2006). Development of a neural-networks tool-wear monitoring system for a turning process, Strojniski vestnik - Journal of Mechanical Engineering, Vol. 52, No. 11, 763-776

[19] Yap, H. J.; Taha, Z.; Lee, J. V. (2008). VR-based robot programming and simulation system for an industrial robot, International Journal of Industrial Engineering - Theory, Application and Practice, Vol. 15, No. 3, 314-322

[20] Kolakovic, I.; Dovic, D. (2009). Simulation of the solar domestic hot water system operation, Technical Gazette, Vol. 16, No. 1, 3-9 